\title{
Influence of Age on Lung Function Tests
}

\author{
Pruthi $^{1}$, N., \& Multani ${ }^{2}$, N.K.
}

${ }^{1}$ PG Student, Dept of Physiotherapy, Punjabi University, Patiala-147001, Punjab

${ }^{2}$ Professor, Dept of Physiotherapy, Punjabi University, Patiala-147001, Punjab

\section{Abstract}

Considerable attempts have been made in the previous studies to study the significant variables affecting the standards for ventilator function including age, height, sex, size of sample tested, racial and ethnic composition, criteria for normality, tobacco smoking, environmental conditions, altitude of residence etc. The present study was necessitated as very few studies have been conducted in northern India to study the effect of age on pulmonary function tests. Study was performed on 50 subjects under the age group of 2575 years, further divided into 5 age groups: 25-35 years, 36-45 years, 46-55 years, 56-65 years and 66-75 years. This was a cross-sectional design, which was performed in the Department of Physiotherapy. The values of all lung function tests, namely, $\mathrm{FVC}, \mathrm{FEV}_{1}, \mathrm{PEFR}, \mathrm{FEV}_{1} / \mathrm{FVC}, \mathrm{SVC}$ and $\mathrm{MVV}$ were found to be negatively correlated with age $(r=-0.446,-0.495,-0.427,-0.312,-0.392$ and -0.919 , respectively). It was concluded the the lung functions significantly decline with age.

Key words: lung function tests, aging, decline

\section{Introduction}

Ageing process is associated with progressive constriction of the homeostatic reserve of every organ. The most important physiological changes associated with ageing are of respiratory system depicting the decrease in static elastic recoil of the lung, in respiratory muscle performance, and in compliance of the chest wall and respiratory system, resulting in increased work of breathing (Janssens, 2005).

\section{Lung functions decline} throughout adult life, even in healthy persons. Cross sectional analysis have suggested that the decline may go faster after age 70 . Normal aging results in changes in pulmonary, mechanics, respiratory muscle strength, gas exchange and ventilatory control. Increased rigidity of chest wall and a decrease in respiratory muscle strength with aging result in an increased closing capacity and a decreased forced expiratory volume in first second or FEV1 (Knudson et al, 1983).

Culver and Butler (1985) reported that lung function does not necessarily decline in the linear fashion, once thought from age 18 or 20 . Rather it may reach a maximum in the late 20s and then decline, but there is variability in older adulthood depending on lung capacity at the time of lung maturation. Therefore, the present study was conducted to examine the influence of age on lung functions.

Lung function tests are carried out to assess the functioning of the lung and routinely used in clinical practice (Verma et al, 2002). Nevertheless, there are only a few studies that have established reference standards for pulmonary function with age, especially amongst Indian population. 
Interpretation remains the least precise aspect of pulmonary function testing. Of first order is the need to understand the influence of age on Lung functions. Significant variables affecting the standards for ventilatory function include age, height, sex, size of the sample tested, racial and ethnic composition, criteria for normality, tobacco smoking, environmental conditions, altitude of residence, apparatus and techniques. Documentation and standardization of the age related changes are very difficult because of the confounding factors such as increased prevalence of disease, chronic illness, use of medication, sedentary lifestyle and difference in the physiological and chronological age. The present study has been necessitated as very few studies have been conducted in this part of the country to study pulmonary function tests in elderly healthy subjects and to see the effect of age on pulmonary function tests in elderly.

\section{Materials \& Method}

The present study was performed on 50 subjects belonging to five age groups (Age group 1- 25-35 years, age group 2- 36-45 years, age group 3- 46-55 years, age group 4- 56-65 years and age group 5- 66-75 years), 10 in each group, taken from the Punjabi University, Patiala under the age group of 25-75 years. This was a cross-sectional study, which was performed in the Department of Physiotherapy. Study was performed in accordance with ethical considerations of the institute and the consent of all the participants was taken prior to the study. Before beginning with the procedure, the subjects who were selected on the basis of random sampling by applying inclusion criteria, were explained the entire procedure in detail.

The Inclusion criteria included both males and females of age group 2575 years, smokers and non smokers, and the absence of any athletic training. The exclusion criteria included subjects with severe cardiopulmonary problem, neurological impairment, recent musculoskeletal injury and vocal cord problem.

The subjects were assessed using tools as following:

1. A spirometer (ISO certified SPIROEXCEL Medicaid system was used, giving thorough consideration to the factors enhancing accuracy of spirometric analysis and minimizing the sources of error and providing accurate information to confirm clinical diagnosis).

2. A stethoscope (An ISO certified stethoscope was used for the auscultation of bronchial sounds).

3. A weighing machine (A weighing machine with \pm 100 grams accuracy was used to measure the weight of subjects in the present study.

4. A measuring tape (A 3-meter measuring tape was used for anthropometric measurement of the height of subjects)

5. A fatigue rating scale Scale (Friedberg \& Jason, 2002) \& the cigarette dependance scale (Etter et al, 2003) were used.

6. Scale for dyspnoea (given by the New York Association classification of breathlessness, Pryor \& Prasad, 2005) was used.

The various statistical techniques like ANOVA, Post Hoc Analysis, Karl 
Pearson Correlation were used to study the influence of age on lung function tests.

\section{Results}

Description of participants:

Table 1 : Mean and SD of age, BMI, dyspnoea \& PAL for the subjects of different Age-Groups

\begin{tabular}{|c|c|c|c|c|c|c|c|c|c|c|}
\hline \multirow{2}{*}{ Variables } & \multicolumn{2}{|c|}{ 25-35 YEARS } & \multicolumn{2}{|c|}{ 36-45 YEARS } & \multicolumn{2}{|c|}{ 46-55 YEARS } & \multicolumn{2}{|c|}{ 56-65 YEARS } & \multicolumn{2}{|c|}{ 66-75 YEARS } \\
\hline & Mean & SD & Mean & SD & Mean & SD & Mean & SD & Mean & SD \\
\hline AGE & 29.00 & 3.40 & 40.30 & 2.75 & 50.60 & 2.72 & 59.70 & 2.98 & 70.00 & 2.83 \\
\hline BMI & 26.90 & 3.07 & 26.91 & 0.81 & 25.98 & 2.70 & 26.20 & 2.81 & 26.10 & 3.31 \\
\hline DYSPNOEA & 1.00 & 0.00 & 1.00 & 0.00 & 1.00 & 0.00 & 1.60 & 0.52 & 2.10 & 0.74 \\
\hline $\begin{array}{l}\text { Physical Activity } \\
\text { Level (PAL) }\end{array}$ & 5.10 & 2.28 & 4.60 & 2.91 & 5.40 & 2.41 & 1.80 & 1.14 & 1.50 & 1.08 \\
\hline
\end{tabular}

Table 2: Mean and SD of LUNG FUNCTION TESTS for the subjects of different Age-Groups

\begin{tabular}{|c|c|c|c|c|}
\hline \multirow{2}{*}{ Variables } & \multicolumn{2}{|c|}{ 25-35 YEARS } & \multicolumn{2}{|c|}{ 36-45 YEARS } \\
\hline & Mean & SD & Mean & SD \\
\hline \multirow{2}{*}{$\begin{array}{l}\text { FVC }(1 t / \mathrm{min}) \\
\operatorname{FEV}_{1}(1 \mathrm{t} / \mathrm{min})\end{array}$} & 4.44 & 1.15 & 3.48 & 0.43 \\
\hline & 3.75 & 0.77 & 2.96 & 0.36 \\
\hline \multirow{2}{*}{$\begin{array}{l}\text { PEFR(It/sec) } \\
\text { FEV } 1 / \text { FVC(lt/min) }\end{array}$} & 10.18 & 3.78 & 8.36 & 1.37 \\
\hline & 88.82 & 7.93 & 78.10 & 17.52 \\
\hline \multirow{2}{*}{$\begin{array}{l}\text { SVC(lt/min) } \\
\operatorname{MVV(lt/min)~}\end{array}$} & 5.25 & 1.92 & 3.89 & 0.65 \\
\hline & 164.70 & 3.16 & 154.90 & 3.87 \\
\hline \multicolumn{5}{|c|}{$\begin{array}{c}\text { Table 3: Comparison of mean for lung function tests } \\
\text { between } 5 \text { different Age Groups }\end{array}$} \\
\hline \multicolumn{2}{|l|}{ Variables } & F value & \multicolumn{2}{|c|}{ P value } \\
\hline \multicolumn{2}{|l|}{ FVC(lt/min) } & 3.875 & \multicolumn{2}{|c|}{$\mathrm{P}<0.05$} \\
\hline \multicolumn{2}{|l|}{$\operatorname{FEV}_{1}(\mathbf{l t} / \mathrm{min})$} & 4.929 & \multicolumn{2}{|c|}{$P<0.05$} \\
\hline \multicolumn{2}{|l|}{ PEFR(lt/sec) } & 3.514 & \multicolumn{2}{|c|}{$P<0.05$} \\
\hline \multicolumn{2}{|c|}{$\mathrm{FEV}_{1} / \mathrm{FVC}(\mathrm{lt} / \mathrm{min})$} & 2.175 & \multicolumn{2}{|c|}{$P>0.05$} \\
\hline \multicolumn{2}{|l|}{ SVC(lt/min) } & 3.113 & \multicolumn{2}{|c|}{$P<0.05$} \\
\hline \multicolumn{2}{|l|}{ MVV(lt/min) } & 468.79 & \multicolumn{2}{|c|}{$P<0.05$} \\
\hline
\end{tabular}

Table 3 shows the results of comparison of mean for Lung function tests among 5 different age groups through ANOVA. It shows the calculated $F$ value for $F V C, \quad F_{1}$, PEFR, $\mathrm{FEV}_{1} / \mathrm{FVC}, \mathrm{SVC}$ and MVV was 3.875, $4.929,3.514,2.175,3.113$ and 468.79 respectively. This indicates that the difference in the mean values of FVC, $\mathrm{FEV}_{1}$, PEFR, SVC and MVV amongst
The demographic details of participants along with BMI, Dyspnoea and Physical Activity Level (P.A.L.) in different age groups are presented below in Table 1. 
Table 4 presents multiple comparisons for the lung function tests amongst different age groups that has been interpreted from the Post Hoc analysis which shows that, mean difference in FVC is significant only between age groups 1 and $4 . \mathrm{FEV}_{1}$ is significantly different between groups 1 and 4 \& groups 1 and 5; whereas PEFR difference is significant only between groups 1 and 4.

\begin{tabular}{cllll} 
Table 5: Post hoc Analysis for SVC and MVV \\
\hline $\begin{array}{c}\text { Multiple } \\
\text { Comparison } \\
\text { between age } \\
\text { groups }\end{array}$ & $\begin{array}{l}\text { Mean } \\
\text { diff. }\end{array}$ & Sig. & $\begin{array}{l}\text { Mean } \\
\text { diff. }\end{array}$ & Sig. \\
\hline Group 1 Vs 2 & $\mathbf{1 . 3}$ & S & 9.8 & S \\
Group 1 Vs 3 & 0.8 & NS & 19.8 & S \\
Group 1 Vs 4 & 1.8 & S & 29.6 & S \\
Group 1 Vs 5 & 1.6 & S & 61.0 & S \\
Group 2 Vs 3 & $-\mathbf{0 . 5 1}$ & NS & 10.0 & S \\
Group 2 Vs 4 & $\mathbf{0 . 4 5}$ & NS & 19.8 & S \\
Group 2 Vs 5 & $\mathbf{0 . 2 4}$ & NS & $\mathbf{5 1 . 2}$ & S \\
Group 3 Vs 4 & $\mathbf{0 . 9 7}$ & NS & 9.8 & S \\
Group 3 Vs 5 & $\mathbf{0 . 7 6}$ & NS & 41.2 & S \\
Group 4 Vs 5 & $\mathbf{- 0 . 2 0}$ & NS & 31.4 & S \\
\hline
\end{tabular}

Multiple comparisons for the above variables between different age groups can be interpreted from the Post Hoc analysis which shows that, mean differences in SVC between group 1 and 2, group 1 and $4 \&$ group 1 and 5 are significant whereas MVV is significant amongst all the age groups.

Table 6: Correlation of age with lung functions for the subjects of age group from 25-75 years

\begin{tabular}{ccc}
\hline & r value & P value \\
\hline AGE Vs FVC & -0.446 & P $<0.05$ \\
AGE Vs FEV 1 & -0.495 & P $<0.05$ \\
AGE Vs PEFR & -0.427 & $P<0.05$ \\
AGE Vs FEV $/$ FVC & -0.312 & $P<0.05$ \\
AGE Vs SVC & -0.392 & $P<0.05$ \\
AGE Vs MVV & -0.919 & $P<0.05$ \\
\hline
\end{tabular}

Table 6 displays the Karl Pearson correlation values between the age and lung functions within different agegroups. The values of correlation (r) of age with $\mathrm{FVC}, \mathrm{FEV}_{1}, \mathrm{PEFR}, \mathrm{FEV}_{1} / \mathrm{FVC}$, SVC and MVV are given in the table. The values of all lung functions are negatively correlated with age which shows that lung functions significantly decline with age.

\section{Discussion}

Aging of population is a significant product of demographic transition. It is associated with progressive constriction of the homeostatic reserve resulting in homostenosis of every organ. To the best of our knowledge not many studies have been conducted to gather the information regarding pulmonary function tests in different age groups in northern India. Therefore, the major purpose of the present study was to establish the influence of age on pulmonary function tests from a randomized sample of urban population.

In the present study it was found that:

- FVC showed a decline of 28.61 $\%$ with the advancement of age.

- FEV1 showed a decline of 28.54 $\%$ with the advancement of age.

- $\quad$ PEFR showed a decline of 24.86 $\%$ with the advancement of age.

- $\quad$ SVC showed a decline of 30.48 $\%$ with the advancement of age.

- $\quad$ MVV showed a decline of 37.04 $\%$ with the advancement of age.

The present study has shown the values that are almost comparable \& similar to the study conducted amongst elderly Chinese (Woo \& Pang, 1988), with only difference that women and not 
men showed an age related decline in FVC in Chinese. Similar decline with age was obtained in studies conducted on the elderly European males and females; however the values of FVC obtained in both sexes were higher than the present study (Rio et al, 2004). Wu \& Yang (1990) conducted a study on Maximal expiratory flow and volume in Chinese aged 60 years and over. Spirometry and maximal expiratory flow-volume curves in 180 healthy (102 women, 78 men) aged 60 years and over in Taiwan were obtained. $\mathrm{FEV}_{1} / \mathrm{FVC}$ and $\mathrm{V}_{\max } 25 \%$ were negatively correlated with age in the men.

The present findings could be explained on the basis of two major changes to the pulmonary system associated with aging. These changes are decreased elastic recoil and stiffening of the chest wall (Zaugg \& Lucchinetti, 2000). Elastic recoil on the lungs depends on the composition of the connective tissue, and alveolar surface tension produced by surfactant (Dempsey \& Seals, 1995). Very limited evidence suggests that the structure of the connective tissue may be the primary mechanism for age-associated change in elastic recoil. Chest wall stiffness is rather accompanied by an increase in chest anterio-posterior diameter, costal cartilage calcification, narrowing of the intervertebral disks, and change in rib to vertebrae articulations (Zaugg \& Lucchinetti, 2000).

In addition to this, decreases occur with alveolar-capillary surface area, the alveolar septal surface area, and the total surface area of the lung parenchyma (Brody \& Thurlbeck, 1985). This reduces the alveolar surface area available for gas exchange and increase the amount of physiological dead space (Zaugg \& Lucchinetti, 2000).

Changes in the surface area result in a decrease in the diffusion capacity of the lung. Both the loss of surface area and a decrease in pulmonary capillary blood volume contribute to reduced and uneven ventilation to perfusion matching in elders. The resting partial arterial pressure of oxygen declines 5-10 $\mathrm{mm} \mathrm{Hg}$ between the ages $25 \& 75$ years (Dempsey \& Seals, 1995).

Pulmonary functions remain the major biologic variable that is affected by aging. Extent of the ageing process in the lungs shows great inter-individual variations (Thurlbeck \& Wright, 1999). Even in individuals who enjoy apparently good health, there are measurable decrements in function of the respiratory system with age (Campbell, 2008). If it is understood that how such ageing changes could be minimized, it might be possible to improve quality of the "added years" into old age (Pride, 2005). The constantly increasing life expectancy of the general population requires the physicians and physiotherapists to consider more closely the effect of aging on the so called 'normal function' of different organs. Clinically this study has shown that how older people can have meaningful measurements made of $\mathrm{FEV}_{1}$ and $\mathrm{FVC}$, if there is careful attention to technique and data quality. These tests, when combined with an informed evaluation of respiratory symptoms, should lead to the timely and accurate diagnosis of respiratory disorders, which in turn may result in better management by incorporating a good knowledge about the disease and exercise programs for them. 


\section{References}

Brody, J. S. and Thurlbeck, W. M. 1985. Development, growth and aging of the lung. In Fishman, A.P. (Ed). Handbook of Physiology, 3(2): 685-93.

Campbell, E. J. 2008. Aging of the respiratory system. In: Fishman AP (Ed). Fishman's Pulmonary Diseases and Disorders. $4^{\text {th }}$ ed. China: Mcgraw Hill Companies, Inc., 263-76

Culver, B. H. and Butler, J. 1985. Alterations in pulmonary function. In: Principles of Geriatric Medicine Ed. Andes, R., Bierman, E.L. and Hazzard, W.R. McGraw Hill Book Co. Ltd. (London); Chapter 26, 280-287

Dempsey, J. A. and Seals, D. R. 1995. Aging, exercise and cardiopulmonary function. In Holloszy, J. (Ed.) Perspectives in exercise science. New York: Williams \& Wilkins, 4(1): 685-693

Etter, J. F., Houezec, J. L. and Perneger, T. V. 2003. A Self administered questionnaire to measure dependence on cigarettes. The cigarette dependence scale. Neuropsychopharmacology. 28: 359-370.

Friedberg, F. and Jason, L. A. 2002. Selecting a fatigue rating scale. The CFS Research Review, 35: 7-11

Janssens, J. P. 2005. Aging of the respiratory system: Impact on pulmonary function tests and adaptation to exertion. Clin. Chest. Med., 26(3): 469-84
Knudson, R. J., Lebowitz, M. D., Holberg, C. J., Burrows B. 1983. Changes in the normal maximal expiratory flow-volume curve with growth and aging. Am. Rev. Respir. Dis., 127: 725-34.

Pride N B. Ageing \& Changes in Lung mechanics. Eur Respire J 2005; 26:563-5.

Pryor, J. and Prasad, S. 2005. Physiotherapy for respiratory and cardiac problems. Adults and Paediatrics; $3^{\text {rd }}$ Ed: 6

Rio, F. G., Pino, J. M., Dorgham, A. and Villamor, A. J. 2004. Spirometric reference equations for European females and males aged 65-85 years. Eur. Respire. J., 24: 397-405.

Thurlbeck, W. M. and Wright, J. L. 1999. The Aging Lung. In: Thurlbeck's chronic airflow obstruction. Canada: Hamilton, 2(1): 128-31.

Verma, S. S., Sharma, Y. K. and Arora, S. 2002. A multivariate study of some lung function tests at different age groups in healthy Indian males. Ind. J. Chest Dis. Allied Sci., 44: 85-9

Woo, J. \& Pang, J. 1988. Spirometry in healthy elderly Chinese. Thorax, 43: 617-20

Wu, H. D. and Yang, S. C. 1990. Maximal Expiratory Flow and Volume in Chinese aged 60 years and over. J. Formos Med. Assoc., 89(9): 749-55

Zaugg, M. \& Lucchinetti, E. 2000. Respiratory function in the elderly. Anesthesiology Clin. North America, 18: 47-58. 